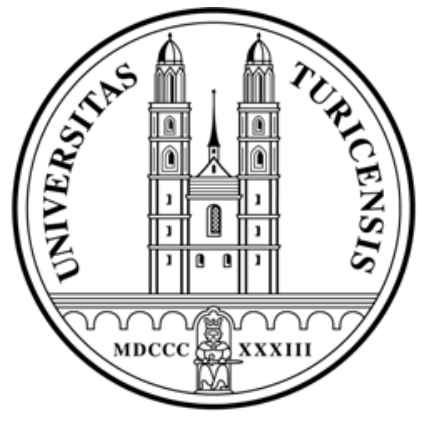

Institute for Empirical Research in Economics

University of Zurich

Working Paper Series

ISSN 1424-0459

Working Paper No. 461

Grain Prices and Mortality in Vienna, 1648-1754

Julia Casutt and Ulrich Woitek

December 2009 


\title{
Grain Prices and Mortality in Vienna, $1648-1754$
}

\author{
Julia Casutt* \\ IERE, University of Zurich \\ Ulrich Woitek \\ IERE, University of Zurich and CESifo, Munich
}

November 2009

\begin{abstract}
Class specific mortality in 17th and 18th Century Vienna shows a cyclical pattern which is related to grain price cycles in the 5-10 years range. This relationship is not stable over time. Applying spectral analysis based on time-varying VARs, it can be shown that at the beginning of the observation period, comovement of grain prices and mortality is considerably high in areas populated by lower classes of society. This comovement cannot be found in richer areas of the city and vanishes over time for the entire population of the city.
\end{abstract}

Keywords: Grain Prices, Mortality, Vienna, Spectral Analysis

JEL Code: N33, N53, N93, C32

*Corresponding Author: Julia Casutt, IERE, University of Zurich, Winterthurerstr. 30, 8006 Zurich, Switzerland, phone: +41446343653, fax: +41446343599, email: jcasutt@iew.uzh.ch. The authors would like to thank Ann Carlos, Markus Cerman, Kent Johansson, Cormac Ó Gráda, Les Oxley, Andreas Weigl, conference participants at the 7th Conference of the European Historical Economics Society, Lund, 2007, the 6th World Congress of Cliometrics, Edinburgh, 2008, and seminar participants at the universities of Zurich, Vienna, and Nuremberg for valuable comments. We are also indebted to Christine Schneeberger for supporting the data research and Chris Young for editorial work. 


\section{Introduction}

In agricultural societies, grains were the most important products: they provided no less than $70 \%$ of human caloric requirements (Neveux 1979, p.79; Achilles 1991, pp.17-23). Therefore, grain prices and their fluctuations had an impact on life and death, reflected only partially in mortality crises related to famine (Fogel, 2004, Chapter 1): chronic malnutrition undermines the immune system, thus making the body prone to infectious diseases. Examples for infections which are definitively exacerbrated by malnutrition are measles, diarrhea, tuberculosis, most respiratory infections, pertussis, most intestinal parasites, cholera, leprosy, and herpes. Malnutrition has a variable impact on typhus, diphtheria, staphylococcus, streptococcus, influenza, syphilis, and systemic worm infections. The impact of nutrition is minimal on smallpox, malaria, plague, typhoid, tetanus, yellow fever, encephalitis, and poliomyelitis (Bellagio Conference, 1983, Figure 3).

In the following, we want to explore class specific cyclical patterns of mortality and grain prices for the city of Vienna in the period from 1648 to 1754. The relationship between food prices and mortality in the short-run is well documented. According to Wrigley and Schofield (1989, p. 399), price variations in pre-industrial England account for about 16\% of the variance of mortality. Another related study is Chevet and Ó Gráda (2006), who analyze the inter-relationship between grain prices and mortality with regard to "La Michodière's Law" (i.e. the inter-relationship of mortality and wheat prices) for France. They conclude that there is evidence for this particular correlation at least for early 18th Century France.

In the long-run, pre-industrial mortality in a city such as Vienna was dominated by epidemics and contagious diseases caused by insufficient hygienic conditions. In addition, degenerative diseases played an important role (Csendes and Opll, 2003, p. 116). Another potential problem in this period were so called subsistence or supply crises. Vienna was exposed to this type of crisis to a lesser extent, because the status as residence city guaranteed stable food supply beyond the typical standard of the Habsburg Empire 
(Weigl 2000b, pp. 162-163, Csendes and Opll 2003, p. 117). ${ }^{1}$ However, there was a considerable part of the population to whom price increases and resulting food shortages did indeed matter with respect to mortality. The lower classes and urban poor accounted for approximately $25 \%$ of the Viennese inhabitants (Weigl 2000b, pp. 198-199; Weigl 2001, p. 51). ${ }^{2}$ Endemic infectious diseases were primarily the problem of these classes, because higher classes had more possibilities to protect themselves (Weigl, 2000a, p. 3). In addition, infant mortality and inequality were related, in particular with regard to illegitimate birth which was a typical lower class phenomenon (Weigl, 2000b, p. 204). ${ }^{3}$

The present paper contributes to a deeper understanding of class specific mortality fluctuations in relation to nutrition. ${ }^{4}$ Unequal access to food and differences in diet were a consequence of increasing social tension caused by economic, political and demographic changes, especially in the first half of the observation period (Bräuer, 1996, pp. 36-43). ${ }^{5}$ Applying spectral analysis based on time-varying VARs, the main findings are that most of the fluctuation in urban mortality is dominated by cycles of 5-10 years. Moreover, fluctuations in grain prices explain suburban mortality fluctuations better than fluctuations in areas populated by higher classes. The paper is structured as follows: in Section 2, the data are introduced. Section 3 presents the method, Section 4 discusses the results, and Section 5 concludes.

\footnotetext{
${ }^{1}$ In the 16 th and 17 th Centuries, greater Vienna had a population of about 60,000 . Until the first official census in 1754, the population tripled to 175,403 (Spielman, 1993, p. 31). Because of the negative rate of natural increase for early modern cities, migration was the key regulator of demographic growth (de Vries, 1984; Knittler, 2000; Weigl, 2000b; Wrigley and Schofield, 1989). In the case of Vienna, population increase was the conseuquence of the position as capital of the Habsburg Empire and residence city of the emperor (Weigl, 2001, pp. 103-105).

${ }^{2}$ Vienna also experienced food riots such as the so called Bäckerrummel in 1805, which involved plundering and a bloody military intervention in the course of a food shortage (Opll, 1981, pp. 58-59).

${ }^{3}$ For the consequences of malnutrition with regard to child mortality see Johansson (2004).

${ }^{4} \mathrm{~A}$ paper that deals with similar questions for the 16 th Century is Landsteiner (2001).

${ }^{5}$ For a detailed discussion of the 17 th Century crisis, see De Vries (1976).
} 


\section{Data}

Figure 1: 17th Century Vienna

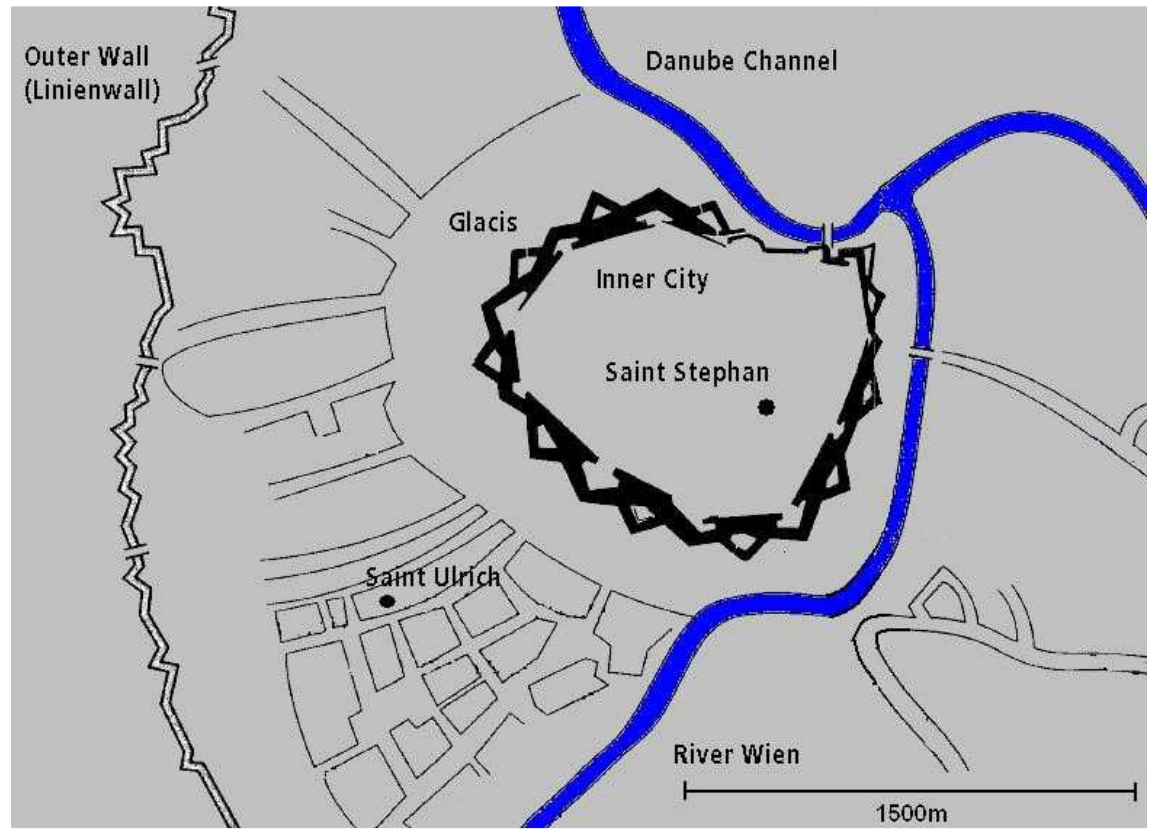

To identify class specific mortality fluctuations, two series of death records and their inter-relationship with grain prices are analysed, the death records of the parishes Saint Stephan and Saint Ulrich. To estimate the missing observations, ${ }^{6}$ we decided to use a multivariate local-linear-trend model, and added a deaths series for Stockerau ${ }^{7}$ (Lehners, 1973) to the data to help interpolate the dynamics. ${ }^{8}$ The investigation period starts in the year 1648, the end of the Thirty Years War. In 1650, greater Vienna had an estimated population of 50,000 inhabitants. 30,000 inhabitants lived in the walled innercity and 20,000 in the suburbs outside the fortress ring (Weigl, 2001, p. 57).

\footnotetext{
${ }^{6}$ Saint Stephan: 1671, 1673, 1676, 1688, 1702, 1707, 1709, 1710, 1712; Saint Ulrich: 1662-1669, 1679-1682, 1701-1704 (because of the razing of the suburbs, we do not interpolate the siege year 1683 for Saint Ulrich).

${ }^{7}$ Stockerau is a village about 25 kilometers in the Northwest of Vienna.

${ }^{8}$ See Section 3 for an explanation of the method.
} 
The inner-city was populated with middle and higher class citizens. After the establishment of Vienna as administrative capital of the Habsburg Empire in 1612, a massive influx of nobility and court employees began, while a considerable part of the residents was dislodged to the suburbs. In 1566, about $21.6 \%$ of the houses were owned by nobility, clergy, court staff and officials. $73.7 \%$ were owned by city officials, merchants, and craftsmen. In 1664 , the proportion of non-bourgeoisie house owners in the inner-city increased up to $39.2 \%$, while the proportion of house-owning citizens such as merchants or craftsmen fell back to $56 \%$ (Lichtenberger, 1977, p. 101).

Especially in the beginning of the investigation period, the inner-city accounted for more inhabitants than the suburbs. The reason for this development was the latent Turkish threat and the need for a fortification system, which restricted suburban growth up to the siege year 1683. As soon as the Turkish siege was repelled successfully, a continuous settlement and growth in the suburbs started. Already in 1754, according to the results of the first official census, the population of Vienna numbered around 175,403 inhabitants, 120,962 of them living in the suburbs (Weigl, 2000b, p. 54).

The vital records of the parish Saint Stephan cover about two thirds of the walled inner-city, as well as a part of the suburbs. Since the parish's suburbs were comparatively less populated areas (Geyer, 1929, pp. 2-6), it can be seen as representing the higher class population of the inner-city. The second parish, Saint Ulrich, was a typical trade suburb with middle class population and higher proportions of lower class inhabitants. ${ }^{9}$ Between 1650 and 1660, it was populated by about 5000 inhabitants (Weigl, 2001, p. 47). In 1783, population increased to 17,450 inhabitants (Weigl, 2000b, p. 367).

The deaths series are displayed in Figure 2. For Saint Ulrich, there are no death records for the years 1683 and 1684, because the suburbs were razed in the course of the Turkish siege. The increase in the number of deaths after 1683 is the result of the above mentioned continuous growth of the suburbs. Nevertheless, all the series show the typical pre-industrial mortality peaks caused by epidemics or war. An example is the Thirty Years War, when the

\footnotetext{
${ }^{9}$ Bräuer (1996, pp. 166-167) found that a substantial part of the Viennese beggars lived in the suburbs.
} 
surroundings of Vienna had been severely affected. During and directly after this period, the city was regularly hit by epidemics such as plague, typhus and dysentery caused by troop movements in and around Vienna (Weigl, 2001, pp. 65-67).

Presumably, the death records of all three parishes do not cover the two severe plague outbreaks in 1679 and 1713 exactly. While there is a peak in the Stockerau series in 1679, Saint Ulrich and Saint Stephan do not show an extraordinary number of deaths. Another source, the Totenbeschauprotokolle ${ }^{10}$ recorded 8000 plague deaths for the entire city, a figure which is probably too low (Schmölzer, 1985, p. 98). One could speculate that in the chaos after the outbreak public records were not kept up to date or that the victims died in hospitals instead of their home parishes. The plague of 1713 is visible in the Saint Ulrich series, but not for Saint Stephan.

To account for population growth, we substract the average growth rate based on the population estimates from the rate of change of the death series (Saint Stephan: 1650-1730: 0.4\% p.a., 1731-1754: 1.3\% p.a.; Saint Ulrich: 1650-1660: 0.0\% p.a., 1661-1754: 0.7\% p.a.). This enables us to look at the impact of price fluctuations on changes in mortality rates.

The grain prices for the period under analysis (Figure 3) come from the collection compiled by Francis Pribram (1938). The prices in this collection can be seen as wholesale prices, because Pribram's information source, the Bürgerspital, was a hospital providing a lot of patients with food, and usually purchased higher amounts of grains. However, it can be assumed that fluctuations of wholesale and retail prices do not diverge substantially. The grains under analysis are wheat, ${ }^{11}$ rye (Korn), barley, and oats, measured in Wiener Metzen, ${ }^{12}$ the unit of account is the Kreuzer. ${ }^{13}$ The correlation of grain price fluctuations in the city with fluctuations of available grain price

\footnotetext{
${ }^{10}$ For information on the Totenbeschauprotokolle as a source, see Weigl (1998).

${ }^{11}$ According to Sandgruber (1982, p. 141), wheat was the most important staple food in Vienna from the 18th Century onwards.

${ }^{12}$ The Wiener Metzen is the local dry measure and contained about 46.25 liters in the observation period (Pribram, 1938, p. 102).

${ }^{13} 1$ florin $=60$ Kreuzer, silver equivalent (gram per florin): 1650-1659: 17.111 g, 16592667:16.812 g; 1667-1683: 15.761 g; 1683-1693: $14.410 \mathrm{~g} ; 1693-1748$ : 12.609 g; 17481750/53: 12.289 g (Pribram, 1938, pp. 28-29).
} 
series from two smaller cities in the vicinity of Vienna (Wels, Weyer, distance to Vienna: 130-170km, data source: Pribram 1938) is relatively low. Therefore, the prices analyzed here can be seen as a reliable indicator for the food situation in the city. Again, we estimated the missing observations using a multivariate local-linear-trend model (Section 3). We converted the price series to growth rates to make them comparable to the mortality growth rates.

Figure 2: Deaths in Saint Ulrich and Saint Stephan, 1648-1754
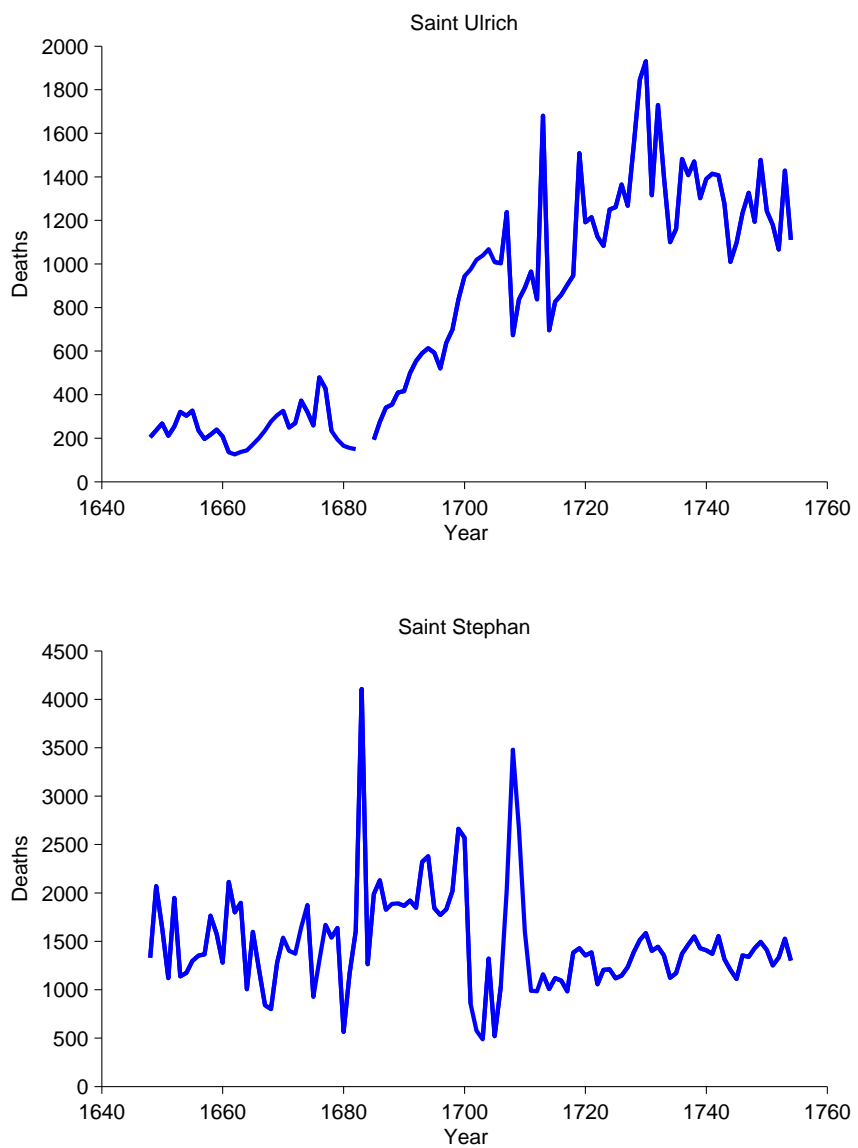

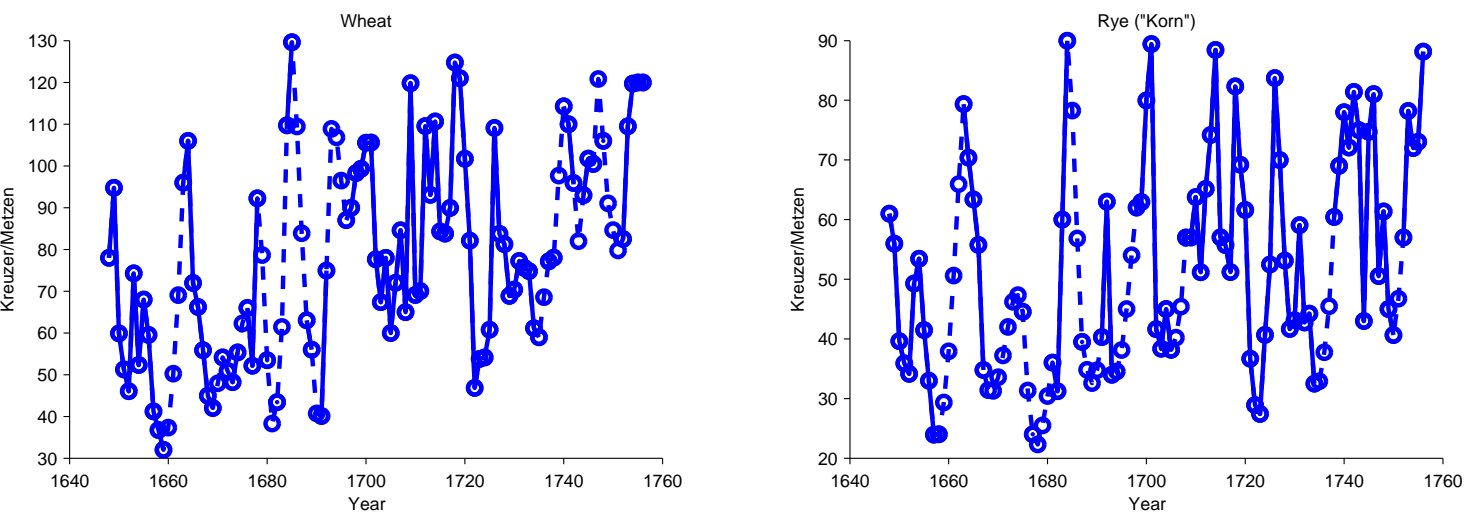

$\infty$
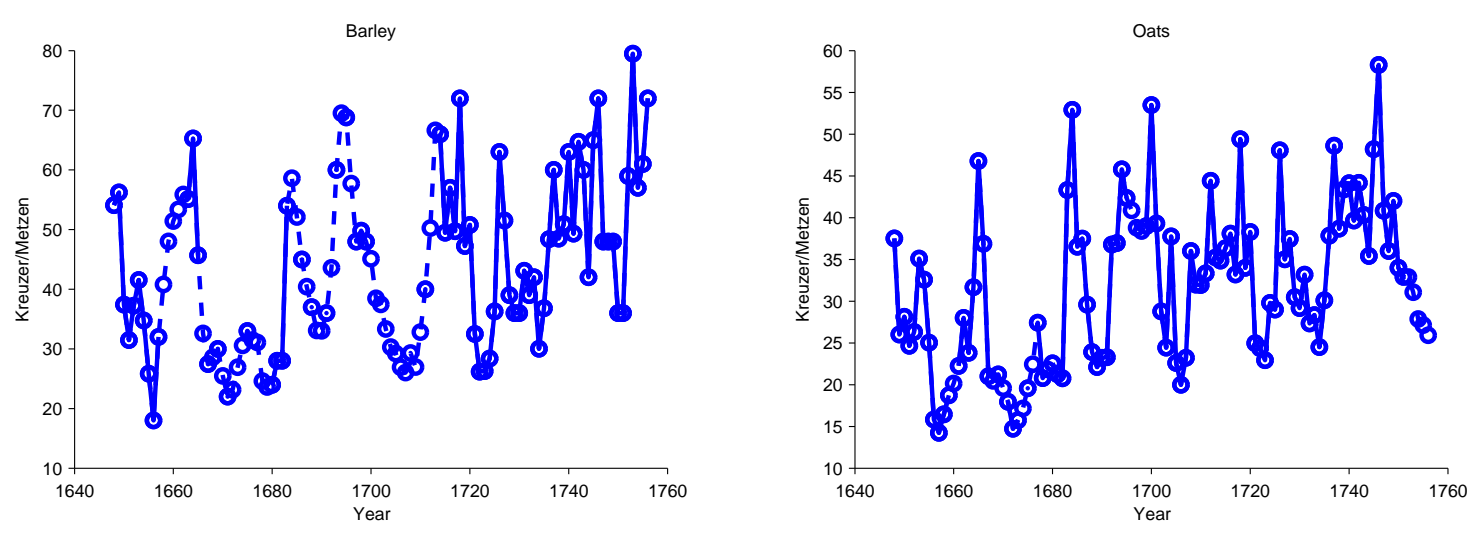

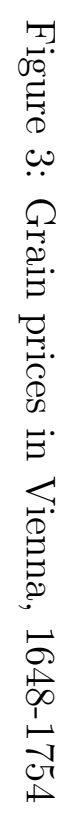




\section{$3 \quad$ Methodolgy}

Spectral Analysis Multivariate autoregressive models (VARs) in the time domain are fitted and transformed into frequency domain. ${ }^{14}$ The starting point of the analysis is a VAR of order $p$ :

$$
\mathbf{x}_{t}=\mathbf{c}+\sum_{j=1}^{p} \mathbf{A}_{j} \mathbf{x}_{t-j}+\boldsymbol{\epsilon}_{t} ; t=1,2, \ldots, T ; \boldsymbol{\epsilon}_{t} \sim i i d(\mathbf{0}, \boldsymbol{\Sigma})
$$

where $\boldsymbol{x}_{t}$ is an $(n \times 1)$ vector of dependent variables, $\mathbf{A}_{j} ; j=1, \ldots, p$ are the $(n \times n)$ parameter matrices, and $\boldsymbol{\epsilon}_{t}$ is an $(n \times 1)$ vector of disturbances, following the usual assumptions. The spectrum of the VAR is defined as

$$
\mathbf{F}(\omega)=\frac{1}{2 \pi} \mathbf{A}(\omega)^{-1} \mathbf{\Sigma} \mathbf{A}(\omega)^{-\star} ; \omega \in[-\pi, \pi],
$$

where $\boldsymbol{\Sigma}$ is the error variance-covariance matrix of the model, and $\boldsymbol{A}(\omega)$ is the Fourier transform of the matrix lag polynomial $\mathbf{A}(L)=\mathbf{I}-\mathbf{A}_{1} L-\cdots-\mathbf{A}_{p} L^{p}{ }^{15}$ Spectral analysis transforms a time series into a set of superimposed harmonic waves in the frequency band $[-\pi, \pi]$. At a frequency $\omega$, the spectrum measures the marginal contribution of the corresponding wave to the total variance of the series. In a frequency interval $\left[\omega_{1}, \omega_{2}\right]$, the area under the spectrum represents the contribution of waves in this range to the total variance. Following previous research on agricultural cycles (Bauernfeind and Woitek, 1996b), we focus on frequency ranges corresponding to cycle lengths of 3-5 years, 5-7 years and 7-10 years.

The dominating frequencies contain important information of the structure of a series such as mortality. For our research question, we are particularly interested in the inter-relationship of two different series, namely mortality and grain prices. For this purpose, the cross spectra (off diagonal

\footnotetext{
${ }^{14}$ Pioneered by Burg $(1967,1968,1975)$, this method is especially suited to deal with economic time series, which are notoriously short. Examples for applications are Hillinger and Sebold-Bender (1992), Bauernfeind and Woitek (1996a), and A'Hearn and Woitek (2001).

${ }^{15} L$ is the backshift operator; the superscript ' $\star$ ' denotes the complex conjugate transpose.
} 
elements of the spectral density matrix) are used to calculate the squared coherency $s c(\omega)$, a measure that is similar to $R^{2}$. It can be used to analyze the relationship between a series $Y_{t}$ (e.g. mortality) and a series $X_{t}$ (e.g. grain prices) in a particular frequency interval $\left[\omega_{1}, \omega_{2}\right]$ by calculating the "explained variance", i.e. the proportion of variance in this particular interval attributable to the other series.

Explained variance does not inform about the co-movement of two series. For this purpose, it is possible to decompose explained variance into an "inphase" component and an "out-of-phase" component. It measures the extent to which the two series reach upper and lower turning points at the same time in a particular frequency interval. Figure 4 gives a graphical impression of the spectral decomposition used in this paper. ${ }^{16}$

Figure 4: Spectral Decomposition

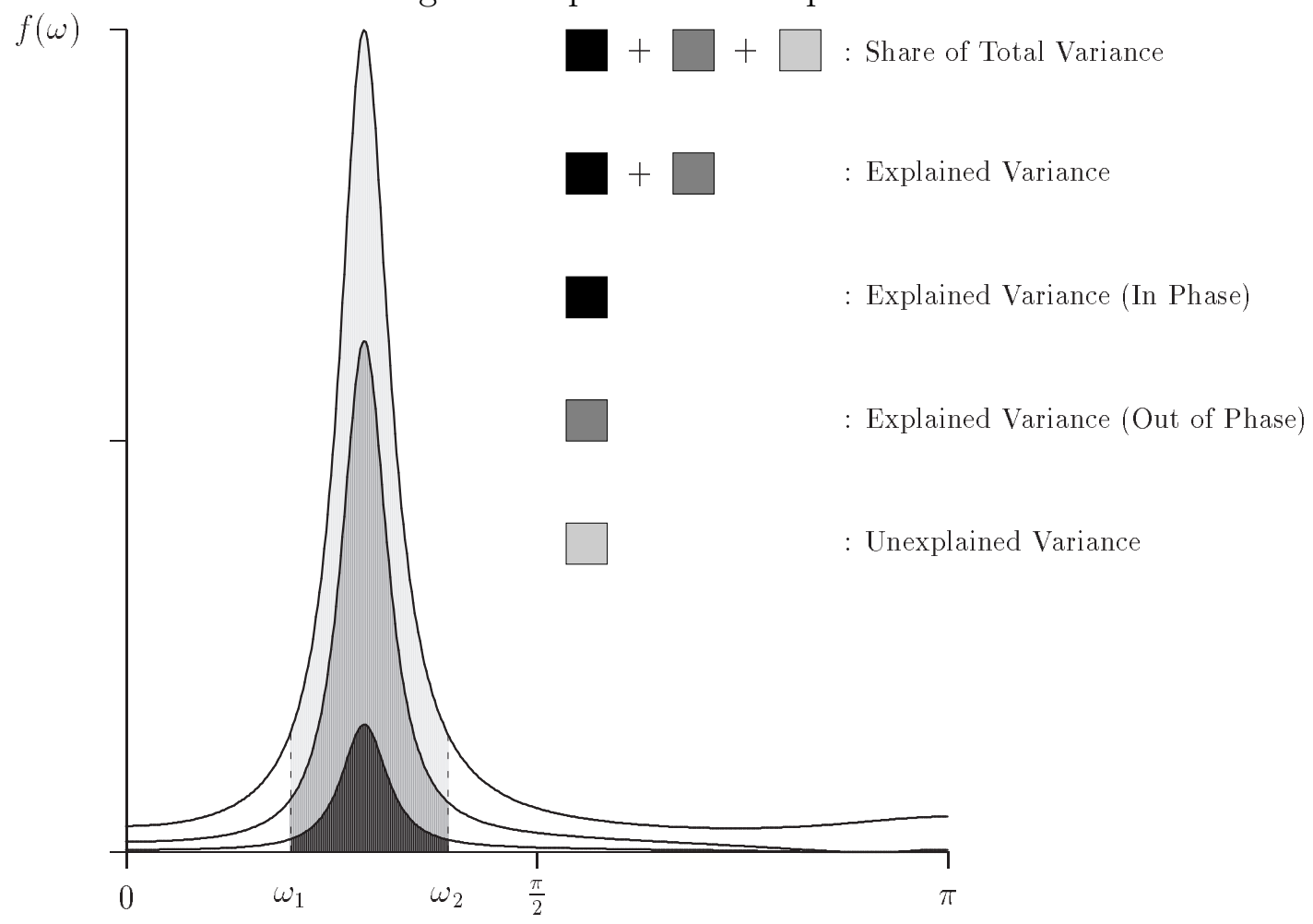

\footnotetext{
${ }^{16}$ See the Appendix for a more formal explanation of the measures.
} 
To obtain a time dependent spectrum, rewrite equation (1) as

$$
\begin{aligned}
\mathbf{x}_{t} & =\mathbf{c}+\sum_{j=1}^{p} \mathbf{A}_{j} \mathbf{x}_{t-j}+\boldsymbol{\epsilon}_{t}= \\
& =\underbrace{\left(\begin{array}{llll}
\mathbf{c} & \mathbf{A}_{1} & \ldots & \mathbf{A}_{p}
\end{array}\right)}_{\mathbf{A}} \underbrace{\left(\begin{array}{llll}
1 & \mathbf{x}_{t-1}^{\prime} & \ldots & \mathbf{x}_{t-p}^{\prime}
\end{array}\right)^{\prime}+\boldsymbol{\epsilon}_{t}=}_{\mathbf{Z}_{t-1}} \\
& =\mathbf{A Z}_{t-1}+\boldsymbol{\epsilon}_{t} ; \boldsymbol{\epsilon}_{t} \sim i i d(\mathbf{0}, \mathbf{\Sigma}) .
\end{aligned}
$$

Treating the parameter matrices as time dependent, the model in equation $\left(1^{\prime}\right)$ can be interpreted as the measurement equation of a state-space model

$$
\mathbf{x}_{t}=\left(\mathbf{Z}_{t-1}^{\prime} \otimes \mathbf{I}\right) \underbrace{\operatorname{vec}\left(\mathbf{A}_{t-1}\right)}_{\boldsymbol{\alpha}_{t-1}}+\mathbf{u}_{t}
$$

with transition equation

$$
\boldsymbol{\alpha}_{t}=\mathbf{T} \boldsymbol{\alpha}_{t-1}+\boldsymbol{\eta}_{t} ; \boldsymbol{\eta}_{t} \sim i i d(\mathbf{0}, \mathbf{Q})
$$

The model is estimated using Maximum Likelihood. ${ }^{17}$ Once the time dependent parameter matrices are estimated, it is possible to obtain a spectral density matrix at each point in time:

$$
\mathbf{F}(\omega)_{t}=\frac{1}{2 \pi} \mathbf{A}(\omega)_{t}^{-1} \boldsymbol{\Sigma} \mathbf{A}(\omega)_{t}^{-\star} ; \omega \in[-\pi, \pi]
$$

Interpolation Both the death series and the grain prices are interpolated using the state-space approach. The underlying model is a local-linear trend for an $n \times 1$ vector of observations $\mathbf{x}_{t}$

$$
\begin{aligned}
\mathbf{x}_{t} & =\boldsymbol{\mu}_{t-1} ; \\
\left(\begin{array}{c}
\boldsymbol{\mu}_{t} \\
\boldsymbol{\beta}_{t}
\end{array}\right) & =\left(\begin{array}{cc}
\mathbf{I}_{n} & \mathbf{I}_{n} \\
\mathbf{0} & \mathbf{I}_{n}
\end{array}\right)\left(\begin{array}{c}
\boldsymbol{\mu}_{t-1} \\
\boldsymbol{\beta}_{t-1}
\end{array}\right)+\underbrace{\left(\begin{array}{c}
\boldsymbol{\eta}_{1, t} \\
\boldsymbol{\eta}_{2, t}
\end{array}\right)}_{\boldsymbol{\eta}_{t}},
\end{aligned}
$$

\footnotetext{
${ }^{17}$ To obtain the likelihood function, we use the Kalman filter. For details, see Harvey (1992).
} 
where level and slope innovations are not correlated with each other:

$$
\boldsymbol{\eta}_{t} \sim N\left(\mathbf{0},\left(\begin{array}{cc}
\mathbf{Q}_{1} & \mathbf{0} \\
\mathbf{0} & \mathbf{Q}_{2}
\end{array}\right)\right)
$$

The data are treated as unobservable levels $\boldsymbol{\mu}_{t}$. In case there are missing values in the vector $\mathbf{x}_{t}$, the elements are replaced with the predictions from the Kalman filter, and the updating step is skipped. ${ }^{18}$

\section{Results}

[Table 1 around here]

The results displayed in Table 1 demonstrate the advantage of frequency domain methods for the issue under analysis. Explained variance calculated for the entire frequency range (2- $\infty$ years) corresponds to an $R^{2}$ in time domain. Compared with this measure, there are ranges with a much higher explained variance. Saint Stephan has an explained variance of 0.10 over all frequencies, but with 0.24 and 0.26 in the 5-7 years and 7-10 years range.

[Table 2 around here]

Overall, the 5-7 years and 7-10 years ranges seem to dominate. For all four grains, explained variance in the parish Saint Ulrich for the 1648-1682 sample is higher than for Saint Stephan. This reflects the different socioeconomic status in the two parishes: inhabitants of the parish Saint Stephan could compensate grain price fluctuations better than those of Saint Ulrich. Vienna's political and demographic rise after the Thirty Years War had a reverse side with an increasing number of impoverished people, in particular craftsmen and laborers. Because of the status of the city, there was a high demand for luxury goods. However, this demand could not be met by the local producers. Instead, luxury goods had to be imported (Chaloupek et al., 1991, p. $43 \mathrm{ff}$ ) or produced in manufactures promoted by mercantilistic

\footnotetext{
${ }^{18}$ For details of the estimation of missing values using the state-space approach, see Harvey (1992, pp. 143-144).
} 
policy (Sandgruber, 1982, p. 33). Business competition induced by the Störer (non-guilded craftsmen) or the Stadguardia (city garrison soliders) with craft privileges weakened the position of the old established guilded craft and trade (Chaloupek et al., 1991, p $101 \mathrm{ff}$ ). This deveolpment is also evidenced by Bräuer (1996, pp. 129-130), who analyses a sample of male beggars in Vienna in 1665: $30.4 \%$ of them were former craftsmen, $18.1 \%$ day labourers and $14.6 \%$ Stadtguardia members.

After the break caused by the Turkish siege in 1683, explained variance is much lower. Obviously, there are changes in the relationship, which motivates the use of time-varying spectra. For Saint Stephan, the grain with the highest explained variance is oats. Based on this finding together with the high inphase component for those grains with high explained variance (Table 2), one could speculate whether grain price fluctuation mattered more when all grains were subject to price increases, reducing the opportunity to substitute.

The results for the time varying spectral measures are displayed in Figures 5 and 6 . To keep the state-space model parsimonious, 4 models are estimated for each of the grains. The measure reported in Figures 5 and 6 is the in-phase proportion of explained variance, representing the comovement of prices and mortality. The cycle range is 5-10 years, because this is the interval which dominates the relationship (Table 1). The result is in line with the finding from above that grain price fluctuations are closer related to mortality cycles in the suburbs compared to the inner-city of Vienna.

In the parish Saint Stephan, comovement is weak at best, and does not show a lot of variation over time. The picture for the parish Saint Ulrich is different: there is considerable variation over time. In general, the relationship becomes weaker, which is especially apparent for the rye price cycles, where the proportion at the beginning of the observation period is above 80 per cent, and almost vanishes after 1740. Our findings are in line with Sandgruber (1982, pp. 115-116), who describes the first half of the 18th Century as a period of improving income in Austria. ${ }^{19}$

\footnotetext{
${ }^{19}$ Weigl $(2000 b$, p.197) states that due to decreasing grain prices, purchasing power increased, which led temporarily to a relative low mortality in this period.
} 
Figure 5: Comovement of Price Cycles and Mortality in Saint Stephan: Proportion of In-Phase Explained Variance (5-7 Years)
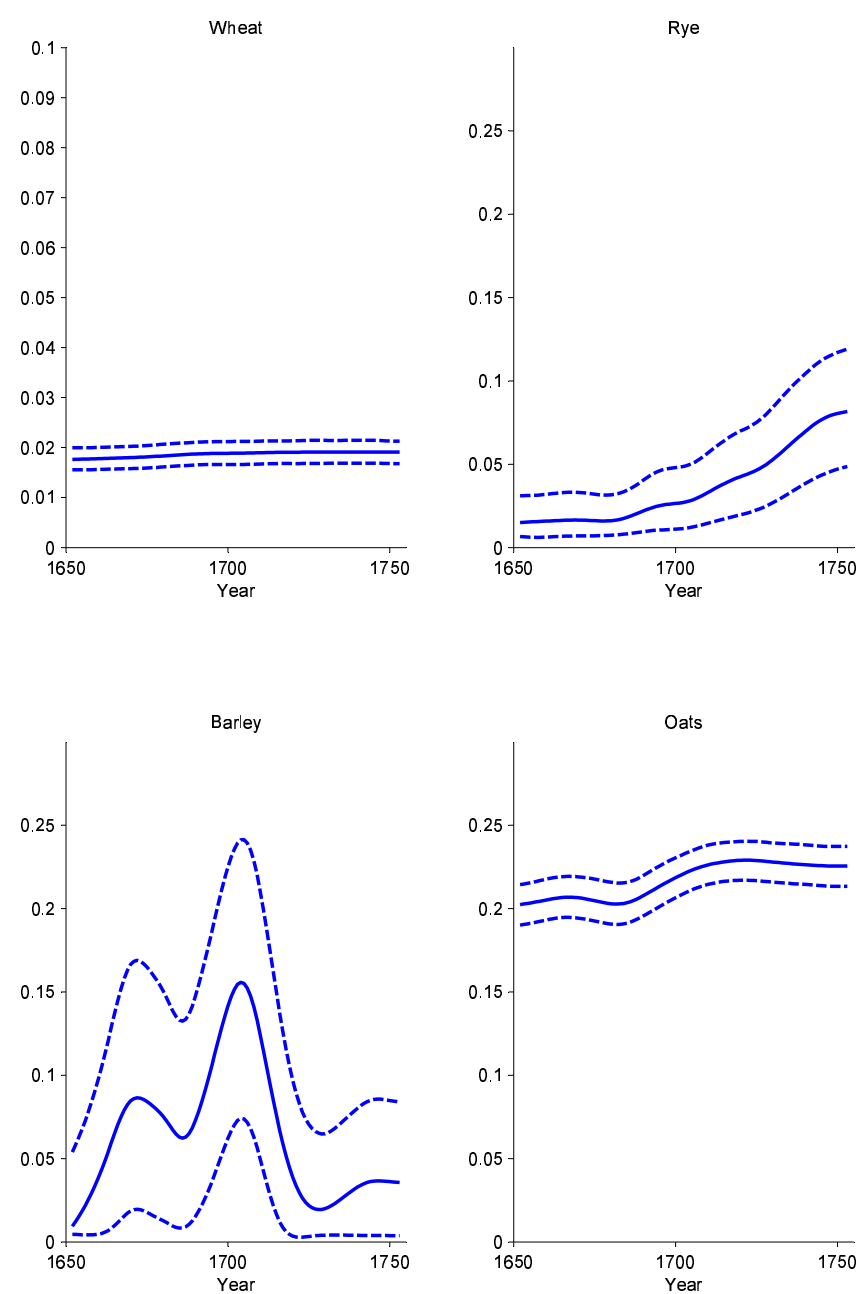

The dotted curves indicate the 95 per cent confidence interval (modified pecentile method, Davidson and MacKinnon 1993, p. 766) based on a Monte Carlo experiment: under the assumption that the state vector is distributed as $\boldsymbol{\alpha}_{t} \sim N\left(\mathbf{a}_{t}, \mathbf{P}_{t}\right)$, where $\mathbf{a}_{t}$ and $\mathbf{P}_{t}$ are outputs from the Kalman filter procedure, 1000 draws of $\boldsymbol{\alpha}_{t}$ are generated at each point in time. The curves are smoothed using a Hodrick and Prescott (1997) filter with smoothing weight $\mu=50$. 
Figure 6: Comovement of Price Cycles and Mortality in Saint Ulrich: Proportion of In-Phase Explained Variance (5-7 Years)
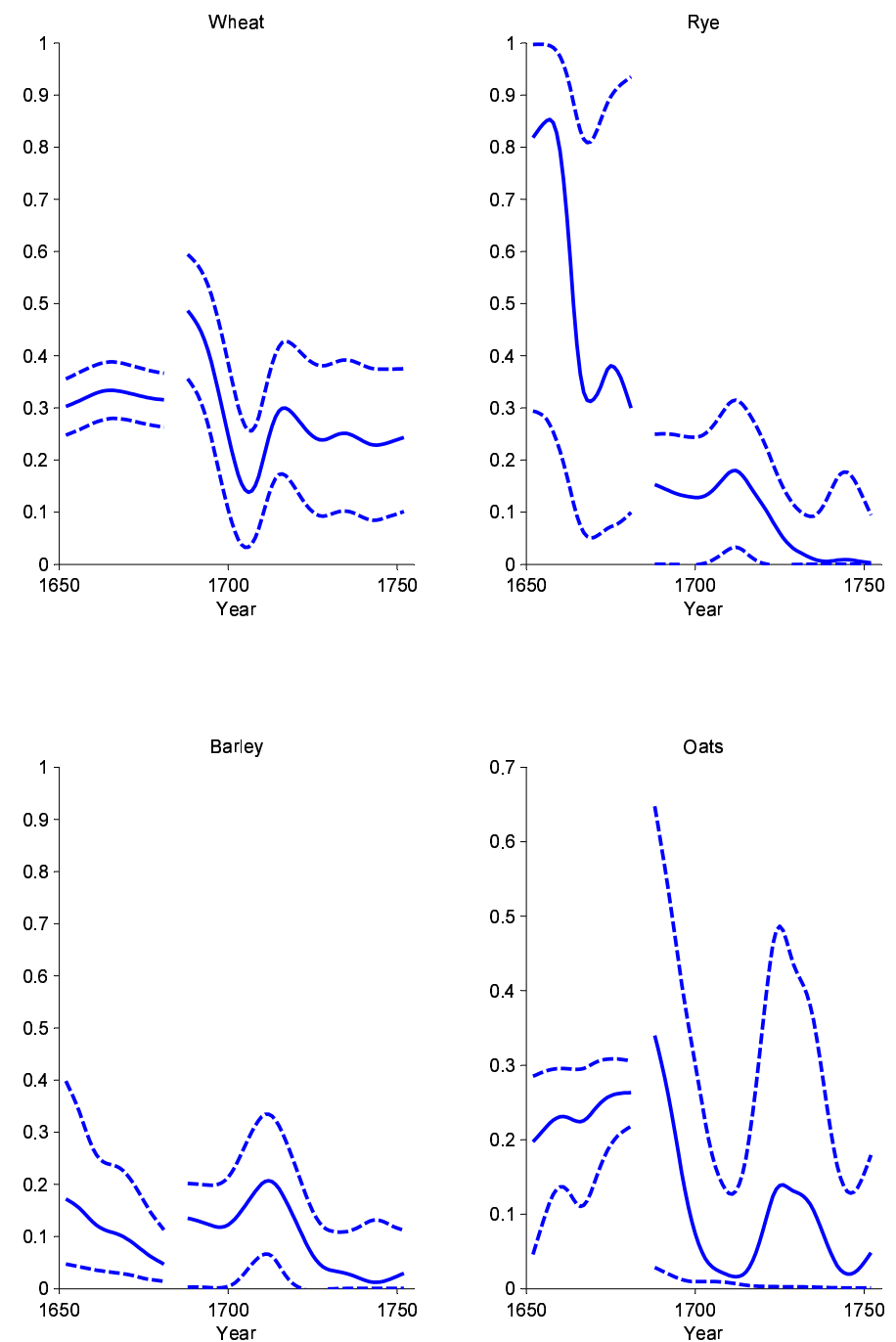

The dotted curves indicate the 95 per cent confidence interval (modified pecentile method, Davidson and MacKinnon 1993, p. 766) based on a Monte Carlo experiment: under the assumption that the state vector is distributed as $\boldsymbol{\alpha}_{t} \sim N\left(\mathbf{a}_{t}, \mathbf{P}_{t}\right)$, where $\mathbf{a}_{t}$ and $\mathbf{P}_{t}$ are outputs from the Kalman filter procedure, 1000 draws of $\boldsymbol{\alpha}_{t}$ are generated at each point in time. The curves are smoothed using a Hodrick and Prescott (1997) filter with smoothing weight $\mu=50$. 


\section{Conclusion}

Socio-economic differences are reflected in the comovement of prices and mortality rates in Vienna. While barley and oats prices did not matter much in the two parishes under analysis, prices for rye before 1700 and wheat prices after had a considerable impact, at least for Saint Ulrich. For the parish Saint Stephan, comovement is low for all grains. In general, comovement between prices and mortality becomes weaker over time, which can be attributed to the overall improvement of living conditions in the first half of the 18th Century. The decrease in comovement with rye prices relative to wheat can be explained by the fact that wheat becomes the prevailing staple food in Vienna during the 18th Century (Sandgruber, 1982, p. 141).

In Vienna, the relationship between grain price cycles and short-term fluctuations in mortality is not due to subsistence crises. The channel of transmission was malnutrition and, related to this, a deterioration of the immune system. The results show that this is particularly the case for the lower classes and urban poor. However, the improvement of urban living conditions in the first half of the 18th Century was only temporary. As known from the literature (Komlos, 1989), the second half of the 18th Century witnessed a deterioration of the standard of living, accompanied by new infections such as cholera and tuberculosis. In the case of Vienna, this can be explained by population growth leading to a deterioration of hygienic conditions and the well known consequences of the beginning of the Industrial Revolution. One can expect that the link between short-term fluctuations in economic activity and mortality re-appeared only a short time later in the second half of the 18th Century. ${ }^{20}$

\footnotetext{
${ }^{20}$ This is in line with the finding that there are cycles in 18th and 19th Century time series on human stature, which show a strong inter-relationship with economic cycles, dependent on the socio-economic status of the group under analysis (Sunder and Woitek, 2005).
} 


\section{References}

Achilles, W. (1991), Landwirtschaft in der frühen Neuzeit, Oldenbourg, München.

A'Hearn, Brian and Ulrich Woitek (2001), 'More international evidence on the historical properties of business cycles', Journal of Monetary Economics 47, 321-346.

Bauernfeind, Walter and Ulrich Woitek (1996a), 'Agrarian cycles in Germany 1339-1670: A spectral analysis of grain prices and output in Nuremberg', Explorations in Economic History 33, 459-478.

Bauernfeind, Walter and Ulrich Woitek (1996b), 'Cyclical characteristics of tithe series in mid franconia and switzerland 1339-1708: An application of maximum entropy spectral analysis', Historical Social Research (Historische Sozialforschung) 21, 122-150.

Bellagio Conference (1983), 'The relationship of nutrition, disease, and social conditions: A graphical presentation', Journal of Interdisciplinary History 14, 503-506.

Brockwell, Peter J. and Richard A. Davis (1991), Time Series: Theory and Methods, 2nd edn, Springer, Berlin, Heidelberg, New York, Tokio.

Bräuer, Helmut (1996), "...und hat seithero gebetlet": Bettler und Bettelwesen in Wien und Niederösterreich während der Zeit Kaiser Leopolds I., Böhlau Wien, Köln, Weimar.

Burg, John Parker (1967), Maximum entropy spectral analysis, in 'Proceedings of the 37th Meeting of the Society of Exploration Geophysicists'. Reprinted in Childers, D. G. (1978), Modern Spectrum Analysis. New York: IEEE Press.

Burg, John Parker (1968), A new analysis technique for time series data, in 'NATO Advanced Study Institute on Signal Processing with Emphasis 
on Underwater Accoustics'. Reprinted in Childers, D. G. (1978), Modern Spectrum Analysis. New York: IEEE Press.

Burg, John Parker (1975), Maximum Entropy Spectral Analysis, PhD thesis, Stanford University.

Chaloupek, Günther, Peter Eigner and Michael Wagner (1991), Wien. Wirtschaftsgeschichte. 1740-1938, Jugend und Volk, Wien.

Chevet, Jean-Michel and Cormac Ó Gráda (2006), 'Grain prices and mortality: A note on "la michodière's law", European Journal of the History of Economic Thought 13, 183-194.

Croux, Christophe, Mario Forni and Lucrezia Reichlin (2001), 'A measure of comovement for economic variables: Theory and empirics', Review of Economics and Statistics 83, 232-241.

Csendes, Peter and Ferdinand Opll, eds (2003), Wien. Geschichte Einer Stadt, Vol. 2, Böhlau, Wien, Köln, Weimar.

Davidson, Russel and James G. MacKinnon (1993), Estimation and Inference in Econometrics, Oxford University Press, Oxford, New York.

De Vries, Jan (1976), The Economy of Europe in an Age of Crisis, 1600-1750, Cambridge University Press, Cambridge.

de Vries, Jan (1984), European Urbanization 1500-1800, Methuen and Co. London.

Fogel, Robert W. (2004), The Escape from Hunger and Premature Death, 1700-2100, Cambridge University Press, Cambridge.

Geyer, Rudolf (1929), Handbuch der Wiener Matriken, Wien.

Granger, Clive W. J. and Paul Newbold (1986), Forecasting Economic Time Series, 2nd edn, Academic Press, London.

Harvey, Andrew C. (1992), Forecasting, Structural Time Series Models and the Kalman Filter, Cambridge University Press, Cambridge. 
Harvey, Andrew C. (1993), Time Series Models, 2nd edn, Harvester Wheatsheaf, New York, London, Toronto, Sydney, Tokio, Singapore.

Hillinger, Claude and Monika Sebold-Bender (1992), The stylized facts of macroeconomic fluctuations, in C.Hillinger, ed., 'Cyclical Growth in Market and Planned Economies', Oxford University Press, London, pp. 63-110.

Hodrick, R.J. and E.C. Prescott (1997), 'Postwar U.S. business cycles: An empirical investigation', Journal of Money, Credit and Banking 29, 1-16.

Johansson, Kent (2004), Child Mortality During the Demographic Transition. A Longitudinal Analysis of a Rural Population in Southern Sweden, 17661894, Almqvist \& Wiksell International, Stockholm.

Knittler, Herbert (2000), Die europäische Stadt in der frühen Neuzeit. Institutionen, Strukturen, Entwicklungen, Verlag für Geschichte und Politik München Oldenbourg.

Komlos, John (1989), Nutrition and Economic Development in the Eighteenth-Century Habsburg Monarchy, Princeton University Press, Princeton, New Jersey.

Koopmans, Lambert H. (1974), The Spectral Analysis of Time Series, Academic Press, New York, San Francisco, London.

Landsteiner, Erich (2001), 'Trübselige Zeit? Auf der Suche nach den wirtschaftlichen und sozialen Dimensionen des Klimawandels im späten 16. Jahrhundert', Österreichische Zeitschrift für Geschichtswissenschaften 12(2), 79-116.

Lehners, Jean-Paul (1973), Die Pfarre Stockerau im 17. und 18. Jahrhundert. Erste Resultate einer demographischen Studie, in H.Helczmanovszki, ed., 'Beiträge Zur Bevölkerungs- und Sozialgeschichte Österreichs', Oldenbourg, München, pp. 373-401.

Lichtenberger, Elisabeth (1977), Die Wiener Altstadt. Von der mittelalterlichen Bürgerstadt zur City, Franz Deuticke Verlag. 
Lütkepohl, Helmut (1991), Introduction to Multiple Time Series Analysis, Springer, Berlin, Heidelberg, New York, Tokio.

Neveux, H. (1979), 'Die langfristigen Bewegungen der französischen Getreideproduktion vom 14.-18. Jahrhundert', Scripta Mercaturae 13, 75-88.

Opll, Ferdinand (1981), 'Studien zur Versorgung Wiens mit Gütern des täglichen Bedarfs in der ersten Hälfte des 19. Jahrhunderts', Jahrbuch des Vereins für Geschichte der Stadt Wien 37, 50-87.

Pribram, Alfred Francis, ed. (1938), Materialien zur Geschichte der Preise und Löhne in Österreich, Vol. 1, Carl Ueberreuters Verlag, Wien.

Priestley, M.B. (1981), Spectral Analysis and Time Series, Academic Press, London.

Sandgruber, Roman (1982), Die Anfänge der Konsumgesellschaft: Konsumgüterverbrauch, Lebenstandard und Alltagskultur in Österreich im 18. und 19. Jahrhundert, Oldenburg München.

Schmölzer, Hilde (1985), Die Pest in Wien, ÖBV Wien.

Spielman, John P. (1993), The City and the Crown: The Imperial Court, 1600-1740, Purdue Universtity Press.

Sunder, Marco and Ulrich Woitek (2005), 'Boom, bust, and the human body: Further evidence on the relationship between height and business cycles', Economics and Human Biology 3, 450-466.

Weigl, Andreas (1998), Soziale Ungleicheit vor dem Tod. Zu den Wiener Mortalitätsverhältnissen gegen Ende des dreissigjährigen Krieges, in S. C.Horn, Sonia und Pils, ed., 'Sozialgeschichte der Medizin - Stadtgeschichte und Medizingeschichte', Thaur, München und Wien, pp. 116-135.

Weigl, Andreas (2000a), 'Demographischer Wandel in europäischen Metropolen', Beiträge zur historischen Sozialkunde 30(3). 
Weigl, Andreas (2000b), Demographischer Wandel und Modernisierung in Wien, Pichler Verlag.

Weigl, Andreas (2001), Residenz, Bastion und Konsumptionsstadt: Stadtwachstum und demographische Entwicklung einer werdenden Metropole, in A.Weigl, ed., 'Wien im Dreißigjährigen Krieg. Bevölkerung - Gesellschaft - Kultur - Konfession', Böhlau Wien, pp. 31-105.

Wrigley, Edward A. and Roger S. Schofield (1989), The Population History of England 1541-1871. A Reconstruction, Cambridge University Press, Cambridge. 


\section{A Spectral Analysis}

The multivariate spectrum of two stationary time series $X_{t}$ and $Y_{t}$ is defined as the Fourier transform of the covariance function $\boldsymbol{\Gamma}_{x y}(\tau), \tau=$ $0, \pm 1, \pm 2, \ldots:^{21}$

$$
\mathbf{F}_{x y}(\omega)=\frac{1}{2 \pi} \sum_{\tau=-\infty}^{\infty} \boldsymbol{\Gamma}_{x y}(\tau) e^{-i \omega \tau} ; \omega \in[-\pi, \pi] .
$$

The diagonal elements are called autospectra and measure the marginal contribution of harmonic waves at the frequencies $\omega \in[-\pi, \pi]$ to the overall variance of the series. Integrating an autospectrum over the frequency band $[\pi, \pi]$, we obtain the variance of the series:

$$
\gamma_{j}(0)=\int_{-\pi}^{\pi} f_{j}(\omega) d \omega, j=X, Y
$$

After dividing the spectrum by the variance, we can calculate the contribution of cyclical components in a frequency band $\left[\omega_{1}, \omega_{2}\right]$ to the overall variance by integrating over the interval (and multiplying by two). Thus it is possible to assess the relative importance of the cyclical components in the frequency bands of interest. In Section 4, this share of variance will be calculated for the ranges 7-10, 5-7, and 3-5 years.

The off-diagonal elements of the spectral density matrix $\mathbf{F}_{x y}(\omega)$ are called cross-spectra. The cross spectrum at frequency $\omega$ is a complex number and given by

$$
f_{x y}(\omega)=c_{x y}(\omega)-i q_{x y}(\omega) ; \omega \in[-\pi, \pi],
$$

where $c_{x y}(\omega)$ is the cospectrum and $q_{x y}(\omega)$ is the quadrature spectrum. The cospectrum measures the covariance between the "in-phase" components of $X_{t}$ and $Y_{t}$, whereas the quadrature spectrum measures the covariance between the "out-of-phase" components. Together with the univariate spectra, the cross spectrum can be used to calculate a measure similar to $R^{2}$ in linear

\footnotetext{
${ }^{21}$ For the following, see Harvey (1993, pp. 175-179), Granger and Newbold (1986, pp. 4853), Brockwell and Davis (1991, pp. 434-443), Priestley (1981, vol. II), and Koopmans (1974, pp. 119-164).
} 
regression analysis. This measure is the squared coherency $s c(\omega)$ :

$$
s c(\omega)=\frac{\left|f_{x y}(\omega)\right|^{2}}{f_{x}(\omega) f_{y}(\omega)} ; \quad 0 \leq s c(\omega) \leq 1
$$

This measure assesses the degree of linear relationship between two series, frequency by frequency. If we are interested in the extent to which the variance of cyclical components of the series $X_{t}$ in the frequency band $\left[\omega_{1}, \omega_{2}\right]$ can be attributed to corresponding cyclical components in series $Y_{t}$, we can use $s c(\omega)$ to decompose the fraction of overall variance in this interval into an explained and an unexplained part:

$$
\int_{\omega_{1}}^{\omega_{2}} f_{x}(\omega) d \omega=\underbrace{\int_{\omega_{1}}^{\omega_{2}} s c(\omega) f_{x}(\omega) d \omega}_{\text {"explained" variance }}+\underbrace{\int_{\omega_{1}}^{\omega_{2}} f_{u}(\omega) d \omega}_{\text {"unexplained" variance }} .
$$

As pointed out by Croux et al. (2001), a measure like the squared coherency presented above is not suited for analysing the comovement of time series, because it does not contain information about possible phase shift between cycles in the series $X_{t}$ and $Y_{t}$. Croux et al. (2001) propose an alternative measure, the so-called dynamic correlation $\rho(\omega)$, which measures the correlation between the "in-phase" components of the two series at a frequency $\omega:$

$$
\rho(\omega)=\frac{c_{x y}(\omega)}{\sqrt{f_{x}(\omega) f_{y}(\omega)}} ; \quad-1 \leq \rho(\omega) \leq 1
$$

Using

$$
s c(\omega)=\frac{\left|f_{x y}(\omega)\right|^{2}}{f_{x}(\omega) f_{y}(\omega)}=\frac{c_{x y}(\omega)^{2}+q_{x y}(\omega)^{2}}{f_{x}(\omega) f_{y}(\omega)}
$$


we further decompose the expression in equation (11):

$$
\begin{aligned}
& \int_{\omega_{1}}^{\omega_{2}} f_{x}(\omega) d \omega=\int_{\omega_{1}}^{\omega_{2}} \operatorname{sc}(\omega) f_{x}(\omega) d \omega+\int_{\omega_{1}}^{\omega_{2}} f_{u}(\omega) d \omega= \\
& =\int_{\omega_{1}}^{\omega_{2}} \frac{c_{x y}(\omega)^{2}+q_{x y}(\omega)^{2}}{f_{x}(\omega) f_{y}(\omega)} f_{x}(\omega) d \omega+\int_{\omega_{1}}^{\omega_{2}} f_{u}(\omega) d \omega= \\
& =\underbrace{\int_{\omega_{1}}^{\omega_{2}} \frac{c_{x y}(\omega)^{2}}{f_{x}(\omega) f_{y}(\omega)} f_{x}(\omega) d \omega}_{\text {"explained" variance (in-phase) }}+\underbrace{\int_{\omega_{1}}^{\omega_{2}} \frac{q_{x y}(\omega)^{2}}{f_{x}(\omega) f_{y}(\omega)} f_{x}(\omega) d \omega}_{\text {"explained" variance (out-of-phase) }}+ \\
& +\underbrace{\int_{\omega_{1}}^{\omega_{2}} f_{u}(\omega) d \omega}_{\text {"unexplained" variance }} .
\end{aligned}
$$

Thus, it is possible to decompose explained variance into the "in-phase" component and the "out-of-phase" component, adding some information on the importance of the phase shift in a frequency interval to the $R^{2}$ interpretation in equation (11) above. 
Table 1: Variance Decomposition: Growth Rates of Mortality

\begin{tabular}{|c|c|c|c|c|c|c|c|c|c|}
\hline & $\begin{array}{l}\text { Period } \\
\text { (Years) }\end{array}$ & (1) & $(2)$ & (1) & $(2)$ & (1) & $(2)$ & (1) & $(2)$ \\
\hline & $2-\infty$ & 0.39 & 0.25 & 0.23 & 0.15 & 0.39 & 0.22 & 0.28 & 0.16 \\
\hline & & $(0.33,0$ & $13,0.6$ & $.23,0.8$ & $11,0$. & $34,0.8$ & $.13,0$. & $25,0.8$ & $.11,0.54)$ \\
\hline & $3-10$ & 0.47 & 0.29 & 0.18 & 0.09 & 0.38 & 0.17 & 0.30 & 0.21 \\
\hline & & $(0.44,0.9$ & $09,0.6$ & $.15,0.8$ & $.04,0$. & $34,0.8$ & $.07,0.5$ & $36,0.8$ & $.11,0.64)$ \\
\hline & $7-10$ & 0.38 & 0.14 & 0.48 & 0.18 & 0.60 & 0.19 & 0.56 & 0.38 \\
\hline & & $(0.30,0$. & $00,0.5$ & $.33,1.0$ & 01,0 . & $38,1$. & $.00,0$ & 34,1 . & $.00,0.72)$ \\
\hline & $5-7$ & 0.45 & 0.09 & 0.12 & 0.07 & 0.38 & 0.22 & 0.31 & 0.22 \\
\hline & & $(0.28,0$. & $00,0$. & $.12,0.8$ & $.00,0.5$ & $25,0.9$ & $.00,0.6$ & 21,0 . & $.01,0.70)$ \\
\hline & $3-5$ & 0.49 & 0.37 & 0.13 & 0.07 & 0.34 & 0.15 & 0.24 & 0.17 \\
\hline 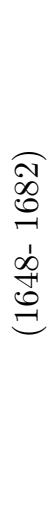 & & $(0.38,0.9$ & $09,0.7$ & $15,0.7$ & 01,0 . & $33,0.8$ & $.02,0$ & 23,0 & $03,0.61)$ \\
\hline \multirow{10}{*}{ 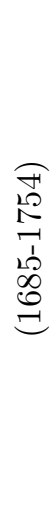 } & $2-\infty$ & 0.05 & 0.03 & 0.17 & 0.16 & 0.15 & 0.14 & 0.11 & 0.09 \\
\hline & & $(0.03,0$. & 01,0 . & $.08,0.3$ & $.04,0$. & 08,0 . & $.05,0$ & 05,0 & $.01,0.26)$ \\
\hline & $3-10$ & 0.09 & 0.06 & 0.11 & 0.09 & 0.17 & 0.15 & 0.06 & 0.02 \\
\hline & & $(0.04,0 . \mathrm{s}$ & $00,0.1$ & $.04,0.3$ & $00,0.2$ & $05,0.4$ & $.01,0$. & $02,0.2$ & $.00,0.14)$ \\
\hline & $7-10$ & 0.10 & 0.08 & 0.09 & 0.04 & 0.08 & 0.04 & 0.06 & 0.02 \\
\hline & & $(0.00,0$ & $00,0.2$ & $.00,0.3$ & $.00,0$. & $00,0.3$ & $.00,0$ & $00,0$. & $.00,0.17)$ \\
\hline & $5-7$ & 0.16 & 0.14 & 0.15 & 0.09 & 0.16 & 0.11 & 0.11 & 0.03 \\
\hline & & $(0.01,0.4$ & $00,0.3$ & $.02,0.4$ & $.00,0.2$ & $01,0.4$ & .00 & 0 & $.00,0.18)$ \\
\hline & $3-5$ & 0.07 & 0.04 & 0.10 & 0.09 & 0.19 & 0.17 & 0.05 & 0.01 \\
\hline & & $(0.02,0$. & $00,0.1$ & $02,0.3$ & 00,0 & $03,0.4$ & 00,0 . & 01,0 . & $.00,0.15)$ \\
\hline \multirow{10}{*}{ 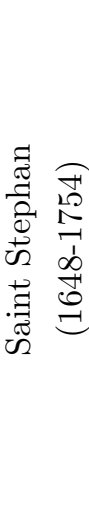 } & $2-\infty$ & 0.10 & 0.04 & 0.07 & 0.04 & 0.05 & 0.04 & 0.18 & 0.15 \\
\hline & & $(0.06,0$. & $00,0.1$ & $.03,0.2$ & $.01,0$. & $01,0$. & $.00,0$. & $11,0 . \mathrm{a}$ & $.06,0.30)$ \\
\hline & $3-10$ & 0.15 & 0.03 & 0.09 & 0.04 & 0.04 & 0.03 & 0.27 & 0.21 \\
\hline & & $(0.06,0 . \mathrm{s}$ & $00,0.1$ & $.04,0.2$ & $.00,0$. & $01,0.1$ & $.00,0.1$ & $14,0.4$ & $.06,0.38)$ \\
\hline & $7-10$ & 0.26 & 0.06 & 0.17 & 0.11 & 0.06 & 0.05 & 0.26 & 0.18 \\
\hline & & $(0.08,0.5$ & $00,0.1$ & $.02,0.4$ & $.00,0$. & $00,0.2$ & $.00,0.1$ & $10,0.5$ & $.00,0.35)$ \\
\hline & $5-7$ & 0.24 & 0.05 & 0.13 & 0.07 & 0.05 & 0.05 & 0.30 & 0.25 \\
\hline & & $(0.06,0.4$ & $00,0.1$ & $.01,0.3$ & $.00,0.2$ & $00,0.2$ & $.00,0.1$ & $12,0.5$ & $.06,0.43)$ \\
\hline & $3-5$ & 0.07 & 0.01 & 0.05 & 0.00 & 0.03 & 0.02 & 0.25 & 0.20 \\
\hline & & $(0.01,0.2$ & $00,0.0$ & $01,0.1$ & $00,0$. & $00,0.1$ & $.00,0$. & $09,0$. & $.03,0.38)$ \\
\hline
\end{tabular}

\section{Notes:}

(1): explained variance; (2): in-phase component.

The numbers in brackets are the limits of 95 per cent confidence intervals based on 1000 bootstrap replications of the underlying VAR (Lütkepohl, 1991, pp. 495-497). The confidence intervals are calculated using the modified percentile method (Davidson and MacKinnon, 1993, p. 766). 
Table 2: In-Phase Proportion of Explained Variance

\begin{tabular}{|c|c|c|c|c|c|}
\hline & Periods & Wheat & Rye & Barley & Oats \\
\hline \multirow{10}{*}{ 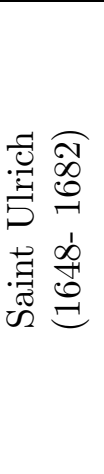 } & \multirow[t]{2}{*}{$2-\infty$} & 0.63 & 0.63 & 0.57 & 0.58 \\
\hline & & $(0.27,0.86)$ & $(0.30,0.89)$ & $(0.26,0.83)$ & $(0.25,0.85)$ \\
\hline & \multirow{2}{*}{$3-10$} & 0.62 & 0.49 & 0.44 & 0.70 \\
\hline & & $(0.21,0.89)$ & $(0.19,0.90)$ & $(0.15,0.80)$ & $(0.26,0.91)$ \\
\hline & \multirow[t]{2}{*}{$7-10$} & 0.37 & 0.37 & 0.32 & 0.68 \\
\hline & & $(0.00,0.80)$ & $(0.01,0.89)$ & $(0.01,0.85)$ & $(0.11,0.98)$ \\
\hline & \multirow[t]{2}{*}{$5-7$} & 0.19 & 0.57 & 0.57 & 0.71 \\
\hline & & $(0.00,0.76)$ & $(0.11,0.99)$ & $(0.04,0.93)$ & $(0.15,1.00)$ \\
\hline & \multirow[t]{2}{*}{$3-5$} & 0.75 & 0.57 & 0.45 & 0.71 \\
\hline & & $(0.29,0.99)$ & $(0.14,0.95)$ & $(0.10,0.86)$ & $(0.21,0.96)$ \\
\hline \multirow{10}{*}{ 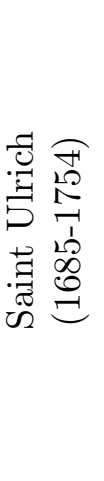 } & \multirow[t]{2}{*}{$2-\infty$} & 0.51 & 0.95 & 0.93 & 0.86 \\
\hline & & $(0.24,0.95)$ & $(0.56,0.99)$ & $(0.56,1.00)$ & $(0.37,0.99)$ \\
\hline & \multirow[t]{2}{*}{$3-10$} & 0.64 & 0.80 & 0.85 & 0.26 \\
\hline & & $(0.20,0.97)$ & $(0.25,0.99)$ & $(0.35,0.99)$ & $(0.01,0.84)$ \\
\hline & \multirow[t]{2}{*}{$7-10$} & 0.78 & 0.42 & 0.56 & 0.30 \\
\hline & & $(0.14,1.00)$ & $(0.00,0.95)$ & $(0.07,1.00)$ & $(0.00,0.95)$ \\
\hline & \multirow[t]{2}{*}{$5-7$} & 0.89 & 0.59 & 0.71 & 0.30 \\
\hline & & $(0.25,1.00)$ & $(0.08,1.00)$ & $(0.17,1.00)$ & $(0.00,0.92)$ \\
\hline & \multirow[t]{2}{*}{$3-5$} & 0.49 & 0.93 & 0.90 & 0.23 \\
\hline & & $(0.08,0.93)$ & $(0.26,1.00)$ & $(0.33,1.00)$ & $(0.01,0.87)$ \\
\hline \multirow{10}{*}{ 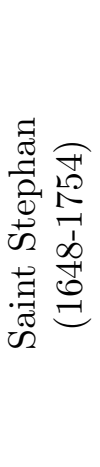 } & \multirow[t]{2}{*}{$2-\infty$} & 0.36 & 0.61 & 0.91 & 0.80 \\
\hline & & $(0.12,0.76)$ & $(0.26,0.93)$ & $(0.42,0.98)$ & $(0.49,0.96)$ \\
\hline & \multirow[t]{2}{*}{$3-10$} & 0.18 & 0.44 & 0.86 & 0.78 \\
\hline & & $(0.01,0.58)$ & $(0.12,0.90)$ & $(0.17,0.97)$ & $(0.42,0.98)$ \\
\hline & \multirow[t]{2}{*}{$7-10$} & 0.24 & 0.63 & 0.85 & 0.68 \\
\hline & & $(0.00,0.64)$ & $(0.18,1.00)$ & $(0.10,1.00)$ & $(0.28,1.00)$ \\
\hline & \multirow[t]{2}{*}{ 5-7 } & 0.19 & 0.53 & 0.96 & 0.82 \\
\hline & & $(0.00,0.57)$ & $(0.11,1.00)$ & $(0.12,1.00)$ & $(0.45,1.00)$ \\
\hline & \multirow[t]{2}{*}{$3-5$} & 0.11 & 0.10 & 0.80 & 0.80 \\
\hline & & $(0.00,0.68)$ & $(0.01,0.79)$ & $(0.10,1.00)$ & $(0.40,1.00)$ \\
\hline
\end{tabular}

Notes:

The numbers in brackets are the limits of 95 per cent confidence intervals based on 1000 bootstrap replications of the underlying VAR (Lütkepohl, 1991, pp. 495-497). The confidence intervals are calculated using the modified percentile method (Davidson and MacKinnon, 1993, p. 766). 